\title{
The Abolition of Dual Administration of NGOs in China: Imperatives and Challenges
}

\author{
Yongjiao Yang, Xiongxiong Zhang, Delong Tang, and Mick Wilkinson
}

\begin{abstract}
The abolition of dual administration of NGOs in China has brought it with many challenges for development and governance of NGOs. In the context of China, the decisive role the government plays in NGOs development, which is criticized by many scholars, is the result of the Chinese history, political culture and also the need of NGOs. Suggestions for new approaches to NGO development with the abolition of dual administration are thus discussed from the perspective of value-based partnership between NGOs and the government, and securing public trust.
\end{abstract}

Index Terms - China, dual administration, NGO-government relation, partnership, public trust.

\section{INTRODUCTION}

China is experiencing the most profound transformation in her history since 1970s. Economic development and social changes have provided more space and tremendous vitality for the third sector, making NGOs indispensable forces in filling the vacuum left by the withdrawal of the state. Advantages and strengths of NGOs enable them to live up to expectations of the public and state. Because of their unique position outside the market and the state, generally smaller scale, connections to citizens, flexibility, capacity to promote private initiative in support of public purposes, and their contributions to building "social capital", charities have been regarded as strategically important participants in the search for a "middle way" between the market and the state [1].

However, because of China's history and political culture, China's NGOs may always have closer relations with the state than their Western counterparts do. NGOs exist within limits defined by the state, and the state can both enable and impede their development based on policy changes since 1949. Chinese NGOs nowadays can be characterised as existing in a transitional stage between complete dependence on the government and some degree of autonomy from it. However, whether initiated by government agencies or individuals, great majority of NGOs are required or tend to affiliated with government and its agencies for administrative and financial support. It attracts much criticism that NGOs in China lack autonomy and genuine civil society does not exist in China [2]-[4].

Manuscript received March 6, 2014; revised May 14, 2014.

Yongjiao Yang is with the University of Hull, UK (e-mail: yangyongjiao11@gmail.com).

Xiongxiong Zhang is with the Durham University, UK.

Delong Tang is with the School of Humanities and Social sciences, University of Science Technology Beijing.

Mick Wilkinson is with the University of Hull.
This point of view is popular among some scholars although it fails to capture China's uniqueness.

Although the Chinese government remains the most decisive component in the development of NGOs, it is gradually withdrawing from many responsibilities, making great efforts to adapt to new situations and initiate new policies to let society expand. The most significant change in China's official policy toward NGOs since the late 1970s is the abolition of dual administration for trade association and chamber of commerce, NGOs working for technology, social welfare and community services initiated in 2013[5]. This policy endows China's NGOs more autonomy. Since NGOs are not required to register with a professional supervisory agency ("yewu zhuguan danwei" and/or "guakao danwei") before register with the Ministry of Civil Affairs (MOCA) any more, they are able to make independent decisions on programme operation and organization management. However, there are many challenges after the abolition of dual registration. For many NGOs, the tie with "yewu zhuguan danwei" and "guakao danwei" with regard to financial support is broken. They have to shift the focus to the membership fee and charitable donation for financial resources. For NGO governance, it underlines the demand for a new NGO-state relation focusing on partnership, legal system improvement, and strengthening NGO supporting network. Therefore, the abolition of dual registration is a double-edged sword.

Under this background, this paper first looks at the government dominated NGO governance in China and its transformation since 1990s. It then reveals many challenges for governance and NGO development with the abolition of dual registration. Finally, suggestions for new approach of NGO development are thus discussed from the perspective of partnership between NGOs and the government, and public trust.

\section{GOVERNMENT-DOMINATED NGO GOVERNANCE AND TRANSFORMATION}

\section{A. NGOs in China}

The term NGO was introduced to China when Beijing prepared to host the 4th World Conference on Women of the United Nations in 1995 [6]. Since then, Chinese scholars have used both the terms NGO (non-government organization) and NPO (non-profit organization) to refer to organizations that are not government managed. NGO is defined as an organization possessing the following characteristics: formally organized, private, self-governing, non-profit-distributing, socially oriented, and voluntary [7]. 
According to official documents, "NGO" in China, which are commonly referred to as "social organization", includes all organizations and institutions that are outside of the state system and operates as non-profits [8].

China's most recent official classification divides all entities that are not government-managed and that operate as nonprofits into three groups: SUs (social units), NGNCEs (non-governmental non-commercial enterprises) and foundation. SUs include various associations, chambers of commerce, and federations. NGNCEs are income-making institutions that do not produce products but provide social or professional services. Foundations aim to raise funds for charitable purposes and provide financial support for SUs. At the end of 2012, there are approximately 499,000 NGOs in China, which is $8.1 \%$ more than the previous year. Among them, there are around 271,000 SUs, 225,000 NGNCEs and 3092 foundations [8].

Prior the communist victory in 1949, there were an estimated 26,126 social organizations (such as guilds, academic and religious groups) in Nationalist-controlled areas of China [9]. During the immediate aftermath of the civil war, most of those organizations were abolished and by 1965 , only 100 government-dominated and 6, 000 similarly operated NGOs remained at the national and local levels respectively [10]. The political control loosened after Deng Xiaoping's reform in 1978 and organizations of variant forms flourished. It was not until the 1989 student movement that the government restarted to tighten up the development of NGOs by introducing a dual system of registry [6]. Based on the new registry system, a NGO cannot get its "birth certificate" from the Ministry of Civil Affairs (MOCA) before getting approval from its "professional" supervision agencies. Despite the regulatory restriction, the NGOs grew rapidly due to mounting social needs. In order to curd the rapid growth and influence of NGOs, a new series of administrative regulations is promulgated [11], [12]. These regulations, which granted MOCA's Bureau of Management of NGOs the power to oversee all NGNCEs, are more comprehensive, more detailed, and much stricter than the 1989 system.

\section{B. Dual Registration}

The centrepiece of the NGO governance strategy is the "dual administration" (or "dual registration" as it is commonly termed). It requires NGOs to find a relevant government department or official social organization which will serve as its "professional supervisory unit" (or so-called "mother-in-law" agency) before register with the Ministry of Civil Affairs at national or local levels [12]. The Ministry of Civil Affairs is primarily responsible for registration procedures and compilation of statistics. Before registering with MOCA, each social organisation must first receive approval from a government bureau which exercises professional leadership and guidance in its field. This government professional department (yewu guikou bumen) is responsible for determining the suitability of establishment and day-to-day control of social organisations within its bailiwick. Once the guikou bureau approves the establishment of a social organisation, the professional relationship stipulated by the regulations often becomes a leadership relationship [6].
In many cases, a social organisation is also affiliated with an official counterpart (guakao danwei). These counterparts are usually government organs or official social organizations. This affiliation gives the organisation the bureaucratic identity necessary to function in the highly bureaucratised environment of the Chinese political society. NGOs need government counterparts in order to gain access to housing or office space, and to facilitate many bureaucratic procedures, such as authorisation for foreign travel. In addition, government counterparts often provide at least partial funding as well as part-time staff members for affiliated social organisations. The government counterpart is also responsible for approving the NGO's choice of both leaders and activities. The yewu guikou bumen and guakao danwei facilitate the government's control towards charities making the state-NGO relations complicated.

However, many government departments and official social organizations are unwilling to take the responsibility for NGOs as their "mother-in-law" and thus many NGOs are unable to register with MOCA. It is because the dual registration system is initially designed to share political risks among state bureaus that "mother-in-law" agencies are beholden to the government if any political problems occur in a social organization. Therefore, small independent NGOs have to register as for-profit business firms if they cannot be affiliated with a "mother-in-law" agency. There are indeed a large number of grassroots NGOs illegal and facing many obstacles in their operation, for example, they cannot open a bank account as an organization neither can get benefits from NGO supporting policies.

Dual registration limits the autonomy of NGOs in terms of their finances, personnel, and decision making. Fisher (1998) emphasizes autonomy as the defining criterion for NGOs because it vitalizes an NGO's functions and enables it to influence government, and thus to play a part in the advance of political pluralism [13]. According to this statement, most Chinese organizations, those at the national level in particular, cannot be defined as legitimate NGOs [6]. Thus, it appears that dual registration is the biggest obstacle to the independence of NGOs in China.

Is abolition of dual registration the elixir for "abnormal" development of NGOs in China, particularly from the Western civil society perspective? Before reaching a conclusion, it is necessary to examine: What is the relation between NGOs and the government? How is it influenced by Chinese political culture and history? Is autonomy so important for NGOs in China and if so, why? Does ties with the government benefit NGOs and if so, how?

\section{NGO-State Relationship}

Scholars have established two rather conflicting frameworks for interpreting the most recent China's state-society relationship: civil society and corporatism. The basic characteristics of the "civil society" are voluntary participation, self-regulation, autonomy and separation from the state [9]. Howell (1996) points out that "civil society implicitly assumes an oppositional relation with the state, neglecting the cooperative dimensions... Discussion about civil society was and still is largely concerned with the desire to limit state power" [14]. Unger and Chan (1995) reject civil 
society as an appropriate analytical framework because "it assumes too much independence in associational life in Deng's China". State corporatism, they argue, provides a more accurate description of situations in China [15].

According to Schmitter (1979), corporatism suggests that the state is likely to co-opt organisation leaders, to pre-empt the articulation of demands by establishing organisations in certain key issue areas, to engage in "clientelistic and patrimonialist practices", and to use "physical repression and anticipatory intimidation" [16]. On the basis of this view, Pearson (1994) uses "socialist corporatism" to describe a state corporatism in socialist China, where the state acts to pre-empt the emergence of autonomous groups and the role of the Chinese Communist Party (CCP) remains crucial [17], [18]. White, Howell and Shang (1996), on the other hand, dispute the state corporatist approach. They view the increasing diversity of social organizations, decline of government control, and effective expression of social interests as supporting the idea that civil society provides a useful framework for thinking about China's third sector [9], [19].

Although state-NGO relation is changing in China, the broad picture displays that NGO governance in China is government dominated. It is shaped by Chinese history, tradition and political culture. First, the adoption of corporatist policies on the part of the Chinese state is easier to legitimise, given an intellectual tradition which accepts the notion of the state as the guarantor of the general interest. In traditional Chinese political thought, the Confucian concept of "Li" pursues a universal order established by the government. Besides, the distinction between the public realm of gong and the private realm of si has never been clear. In Confucius society, the officials were called $\mathrm{Fu} \mathrm{Mu} \mathrm{Guan}$ (parent-like officials). The state, acting on the basis of Confucian precepts, was therefore perceived as the guarantor of the public interests. On the contrary, Chinese NGOs did not 'represent' the interests of the public. They are assumed to be state subsidiaries whose authority derived from and complemented that of the state [20].

Additionally, China as a state that pursues socialist development strategies has fewer incentives to allow NGOs to exist as independent identities. Social welfare services are typically provided by either local governments or state-owned enterprises, reducing the need for social welfare NGOs. Socialist development strategies also emphasize the importance of state-led investment in rural development, reducing incentives to allow for independent development NGOs [2]. Besides, the work units ("danwei") in cities and communes in rural areas as self-sufficient entities providing "cradle-to-grave welfare" filling the space that NGOs often inhabit in capitalist society [21].

Indeed, many NGOs are actively seeking closer relations with the state nowadays [22], [10], [6]. Under corporatist system giving NGOs a strong incentive to seek embeddedness, autonomy is not necessarily essential for an NGO to contribute to socio-economic development. Interdependence between government and NGOs may be functional for achieving a positive socioeconomic impact [23]. It is well proven in China where "some NGOs deliberately invite government officials to join their boards of directors and turn themselves into semi-official organizations just to get access to official resources in terms of direct subsidies or political connections that may facilitate their development" [10]. Moreover, without an adequate legal foundation, autonomy may not always be a positive factor in the development of NGOs. The absence of sufficient government supervision and legal regulation has allowed corruption to flourish, especially for local NGOs. Therefore, obtaining independence is not the top priority for most NGOs in China.

Changes of NGO-state relation have been an on-going process since 1990s when China is facing a lot of social problems: increasing unemployment, aging society, insufficient social and health insurance, migration, and environmental deterioration [6]. With a slogan of "Small Government, Big Society", and in the acknowledgement that the state can no longer provide sufficient social services to needy people, the government has to let society expand with a different approach entitled "socializing social welfare". Redistributing functions to society would release the government from heavy financial burdens and inefficient management, and therefore strengthen its ability. Meanwhile, changes in the labour market with economic reforms are slowly making personnel available to non-governmental organisations independent of the government assignment system. Besides, a higher level of income improves people's ability and willingness to support social organizations. Additionally, some of the most important ideas of civil society, such as citizen participation, volunteerism, a sense of social responsibility, pursuit of personal interests, and growing self-confidence in controlling one's own life, have together created a favourable atmosphere for China's NGOs.

With the abolition of dual registration in 2013, Chinese government has made its intention quite clear to transform government-dominated NGO governance to society-oriented NGO development. The key consideration for NGOs is to generate sufficient resources both from the government and the public while maintaining a balanced and positive relationship with them. It needs many efforts from various aspects to address this challenge, which are illustrated in the following section.

\section{BEYOND ABOLITION OF DUAL REGISTRATION: Challenges AND SOLUSiONS}

Under the great pressure of increasing social needs and international criticism, the dual registration was abolished in 2013, if not completely. According to the Scheme for Institution Reform and Function Transformation of the State Council (guowuyuan zhineng jigou he zhineng zhuanbian fangan) announced during the "Two Conference" (National People' s Congress and Chinese people 's political consultative conference) in 2013, dual administration was abolished for trade association and chamber of commerce, NGOs working for technology, public welfare and community service. These four categories of NGOs are allowed to directly register with MOCA without being approved by professional supervision units or "Mother-in-law" agencies [5]. This was a major step towards 
genuine civil society which reflects a loosening of government control towards society. This policy provides much autonomy for these four categories of NGOs as they are not required to be supervised and managed by their "mother-in-law" agencies anymore. Thus they can operate independently and recruit personnel freely. However, it's too early to conclude that the abolition of dual registration is the penacea for correcting "abnormal" development of NGOs in China.

The abolition of dual administration has brought with it many new challenges. Because of the limitation of paper length, this study focuses on two key aspects. First, abolition of dual registration increases the difficulty of NGO governance for MOCA. Because of the insufficient capacity of the MOCA and local bureaus to oversee NGO operations, "Mother-in-law" agencies are necessary to help the government to control NGOs politically and legally. The abolition of dual registration encourages the government to explore a new state-NGO relation. Meanwhile, with the loosening tie with governmental supervision institution, NGOs have to shift their focus to the public and constituents to elicit resources; thus obtaining public trust becomes central to the survival and propensity of NGOs. The following sections examine these key challenges and propose frameworks to address them.

\section{A. Value-Based Partnership between the Government and NGOs}

Although the dual registration is partly abolished, NGOs are still keeping close relations with the government. Under the CCP's political ideology, there are no truly autonomous non-governmental organizations in China according to the idealised Western model. In China, all institutions must conform to the CCP's ideological principles, and all NGOs need the government's political approval as the precondition of registration. Considering this uniqueness of Chinese political environment, the key point is to encourage the government to shift its role from a parent to a client or partner of NGOs. As "constructive interaction" of state and NGOs proposed by Deng and Jing (1992), civil society should be "a private sphere where members of society engage in economic and social activities following the rule of contract and voluntary principle as well as based on autonomous governance; it is also a non-governmental public sphere for participation in policy discussion and decision making" [24]. It emphasizes an equal rather than subordinate position of NGOs. However, this partnership is underdeveloped in China. The Chinese government summarizes its official NGO policy as "nourishment, development, supervision, and regulation" (peiyu, fazhan, jiandu, guanli). Nevertheless, current policy is heavy on regulation and supervision while rather light on nourishment and support.

NGO-government partnership is difficult to manage even in western counties where NGOs are well developed with a long history. It is impossible for NGOs to be totally unaffected by the government in partnership, particularly when obtaining funding from the government. There exists a power imbalance when the sector collaborates with either the government or the business sector, but weak position is revealed as an important strategy enabling NGOs to collaborate with a wide array of different partners, thus accessing a large pool of potential business donors and collaborators [25]. As what has been argued previously, the focus is no longer about how much independence or autonomy NGOs have, if there is any in the collaboration.

It can be argued, however, that the key to a successful partnership is value similarity. Value-based NGO-government partnership is built on the same goal and the same value of NGOs and the government working on with regard to a certain programme in which they collaborate. Salient value similarity (SVS) is important in cooperation of organizations, because it is not only one of factors in explaining trust, but also a significant predictor of it [26]. People or institutions perceiving that they share similar values tend to trust each other more than those who do not [27]-[29]. Earle and Cvetkovich (1995) argue that in some contexts, especially in those with low familiarity, value similarity is indeed of special importance [30]. Therefore, in government- NGO relations, where similar values exist, control is replaced by trust, and government places more confidence and faith in NGOs, leading to increased levels of financial or policy support and looser control over their programmes.

Moreover, value-based collaboration means particularly important for NGOs as it would help them to maintain charitable values and reach their charitable goals. The most prominent trait of a NGO is value-driven based on voluntarism and charitable purposes [31]. Charitable organizations are viewed as "value-driven organizations that prioritize ends other than for-profit organizations' emphasis on enhancing shareholder value or profit; this prioritization gives NGOs a competitive advantage over for-profit and public sector organizations" [32]. There are many cases in which NGOs distorted their values to compromise with the government in order to obtain resources [33]. It could make most NGOs risk reputation for integrity and independence, and could also pose negative influence on quality of programme they work together for.

One means to formalize the relationship between NGOs and the government is to build a framework for partnership, as epitomised in the UK's voluntary sector Compact process [34]. Such framework should at least clarify following areas of collaboration between the government and NGOs: service purchase, policy consultation, capacity building, funding support and project evaluation. Meanwhile, it should also emphasize the principal of independence and voluntarism. As a great progress in China, the General Office of the State Council enacted the Guidance of Government Purchase of Social Services in the October of 2013 [35]. It illustrates principles of social service purchase by the government concerning purchase subject, service provider, purchase content, purchase mechanism, financial management and performance management. However, these are generous principles lack of guidance on the details of implementation. Therefore, building a framework is only the first step, improving the legal system is also important for meaningful progress. 


\section{B. Securing Public Trust: Challenges and Opportunities}

With governmental funding support shrinking since the late 1980s, an increasing number of NGOs in China are dependent on membership fees and service charges. The abolition of dual registration system, which breaks ties with professional supervision agencies in the government, has caused NGOs to shift from focusing on their relations with the government to focusing on their constituents and society. Public donations are playing an increasingly significant role for the survival and thrive of NGOs. Before obtaining public donation, securing public trust is a premise.

Public trust facilitates the sustainable development of charities. Sargeant and Lee (2004) illustrate that higher degrees of trust in a charity are associated with a greater willingness to become a donor and give greater sums. And higher levels of trust improve the possibility that a relationship will be entered into [36]. This may contribute to a long-term partnership and readily available sources of volunteers. Furthermore, where a relationship already exists, levels of commitment will be generated by virtue of the presence of trust. It is helpful for charities to get through hard times brought by economic recession, reductions in government funding and financial scandals. Trust is also particularly important where intangible services are provided that lack objective criteria to assess performance of a relationship which is often the case with charitable activities [37]. Additionally, trust plays an essential role in the image of an organization. Bendapudi et al (1996) claim that a high level of public trust is helpful for a charity to maintain a good social image, which is greatly beneficial both in their fund raising and in their day to day activities [38].

In China, public trust in NGOs has been under great pressure in recent years by scandals involving very familiar, high-profile charities in China. A number of charities, such as China Youth Development Foundation and Lijiang Mothers Association, have abused their expenses, highlighting risk to public trust [39]. When the scandal of Guo Meimei happened in June 2011, the Red Cross in China faced the biggest challenge since being founded, resulting in a sharp decline of donation and volunteers alongside a notorious reputation which turned out very hard to get rid of. The incident of Guo Meimei not only undermined public trust in Red Cross, it also eroded public trust in the whole voluntary sector. According to statistics published by the Chinese government, being significantly affected by this scandal, the amount of total donation to the voluntary sector decreased dramatically from 6.26 billion in May 2011 to 0.84 billion in August 2011 [40].

In an empirical study conducted by Yang (2012) in China, the level of public trust in charities was measured with a scale (15 items) developed in this study on the basis of in-depth interviews and questionnaire surveys. Items of this scale with scores ranging from 0 to 10 reflected the level of trustworthiness of charities. In the process of scale development, it identified five components of public trust in charities: (1) capacity of charity staff; (2) appropriate usage of money; (3) image and reputation of charities; (4) efficiency in management; (5) transparency. The result of measurement shows that the level of public trust of charities in China was very low with the score of each item below six. Components of "image and reputation of charities" and "transparency" achieved the lowest score (3.96 and 4.13 respectively), which underlined the necessity to prioritize the improvement on these two areas [41].

The abolition of dual registration brings great challenge as well as opportunity to generate public trust. Being influenced by the political culture, NGO's governmental affiliation in general helps organizations gain public trust from the Chinese public, particularly for national NGOs. On the other hand, it becomes controversial when NGOs become subordinates of the government in order to obtain financial support. According to the study of Yang (2012), many Chinese people hope charities could be less dependent on the government [41]. The abolition of dual registration provides NGOs the opportunity to evidence their ability to work well independently from the "mother-in-law". It is helpful to win more faith and confidence from Chinese public. A higher level of public trust in NGOs, in turn, facilitates a higher level of independence from the government with a larger pool of public donations.

Besides seizing the opportunity brought by the abolition of dual registration, NGOs should also devote considerable attention to the public perceptions of the efficiency and value of their work, public needs, and the level and means of communication with the public. For the modern philanthropy, main resources of NGOs should be constitutes by donation from the public and business sector together with contract benefit with the government rather than depending on government grant along. In order to sustain themselves in the marketplace, NGOs will be wise to adapt some strategies employed by the business sector, such as customer (donor) management, public opinion survey, marketing and crisis management. Moreover, a network of NGOs to support each other is also needed for a sustainable development in the same way that chambers of commerce in the business sector function.

\section{CONCLUSION}

Taking account of the challenges brought on by the abolition of dual administration, this study underlines the necessity of building partnerships between NGOs and the government and generating public trust. Although the dual registration and administration system are abolished for some categories of NGOs in China, remaining a close relationship with the government is still a key survival strategy for them. In order to move from this one-sided dependency, a value-based partnership is recommended. With the increasingly significance of public donation as funding sources, securing public trust is indispensible for sustainable development of charities.

However, neither establishing a value-based partnership nor building public trust can be an easy target. China is at its transitional stage and is enduring probably the most enormous urbanization in human history. Mass migration brings together people with different values, particularly the traditional-rural value and modern-urban value. Compromises are still being made, consensus has yet to be 
reached and a unified national value has yet to emerge. Faced with this situation, both the government and NGOs have to adapt themselves to the swiftly changing society, thus making it difficult to establish value-based partnership. Apart from the value issue, the emerging urban middle class produced by China's rapid economic growth is generally more critical and has higher expectation towards NGOs than previous generations, thus making it a real challenge for NGO performance to meet their expectation and win their trust. Given the value issue and higher expectation, it is suggested that future research on NGOs should focus on how to establish a value-based partnership with the government and how to build public trust in China's dynamic and ever changing society.

At the meantime, NGO supporting networks are needed for sharing experience, mutual support and better self-regulation. However, given the China's traditional culture and political reality, a western union-like de jure NGO network is not likely to survive so far, while a de facto network might be the solution. Moreover, a framework of cooperation between NGOs and the government is needed to protect rights and articulate responsibility of each party. However, building a framework is not enough; the long-term solution is a completed legal system. Therefore, future research should also look at how to build NGO supporting networks and improve legislation with regard to charity law.

\section{REFERENCES}

[1] L. M. Salamon and S. W. Sokolowski, Global Civil Society: Dimensions of the Nonprofit Sector, Maryland: The Johns Hopkins University Press, 1999, pp.156-167.

[2] Q. Ma, "Defining Chinese nongovernmental organizations," Voluntas, vol. 13, pp. 113-130, 2002.

[3] W. Xia, "Shimin shehui, Zhongguo jinqi nanyan de meng [Civil society, an impossible dream for China in the near future]," Zhongguo Shehui Kexue Jikan [Chinese Social Science Quarterly], vol. 4, pp. 176-182, 1993.

[4] G. Xiao, "Shimen shehui yu Zhongguo xiandaihua de sanchong zhang-ai [Civil society and three obstacles in China's modernization]," Zhongguo Shehui Kexue Jikan [Chinese Social Science Quarterly], vol. 4, pp. 183-188, 1993.

[5] State Council. (March, 2013). Guowuyuan zhineng jigou he zhineng zhuanbian fangan [The scheme for institution reform and function transformation of the State Council]. [Online] Available: http://www.china.com.cn/news/2013lianghui/2013-03/14/content_282 45220_3.htm

[6] Q. Ma, Non-Governmental Organizations in Contemporary China: Paving the Way to a Civil Society? New York, NY: Routledge, 2006.

[7] L. M. Salamon and H. K. Anheier, "In search of the nonprofit sector I: The question of definitions," Voluntas, vol. 3, pp. 125-151, 1992.

[8] Ministry of Civil Affairs. (June, 2013). Mingzheng Tongji Nianjian [Civil statistics annual report]. [Online] Available: http://cws.mca.gov.cn/article/tjbg/201306/20130600474746.shtml

[9] G. White, J. A. Howell, and X. Shang, in Search of Civil Society: Market Reform and Social Change in Contemporary China, New York: Oxford University Press, 1996, pp. 19-68.

[10] K. M. Chan, "The development of NGOs under a post-Totalitarian regime," in Civil life, globalization and political change in Asia, R. P. Weller, Ed. London and New York: Routledge, 2005.

[11] State Council, "Minban feiqiye danwei dengji guanli zhanxing tiaoli [The temporary regulations of non-governmental and non-commercial enterprises]," People's Daily, pp. 3, October, 1998.

[12] State Council, "Shehui tuanti dengji guanli tiaoli [The regulations of registrations of social organizations]," People's Daily, p. 3, October, 1998

[13] J. Fisher, Nongovernment: NGOs and the Political Development of the Third World, West Hartford, CT: Kumarian, 1998, pp. 46-65.

[14] J. Howell, "Striking a new balance: New social organizations in post-Mao China," Capital and Class, vol. 54, pp. 107, 1996.
[15] J. Unger and A. Chan, "China, corporatism, and the East Asian model," The Australian Journal of Chinese Affairs, vol. 33, pp. 29-53, 1995.

[16] P. Schmitter, "Still the century of corporatism?" in the New Corporatism: Social-Political Structures in the Iberian World, F. B. Pike and T. Stritch, Eds. Notre Dame: University of Notre Dame Press, 1979, pp. 154.

[17] M. M. Pearson, "The Janus face of business associations in China: Socialist corporatism in foreign enterprises," The Australian Journal of Chinese Affairs, vol. 30, PP. 25-46, 1994.

[18] S. H. Whiting, "The politics of NGO development in China," Voluntas, vol. 2, pp. 16-48, 1991.

[19] Q. Ma, "The governance of NGOs in China since 1978: How much autonomy?" Nonprofit and Voluntary Sector Quarterly, vol. 31, pp. 305-328, 2002.

[20] J. Fewsmith, "From guild to interest group: The transformation of public and private in late Qing China," Comparative Studies in Society and History, vol. 25, pp. 617-640, 1983.

[21] C. Heurlin, "Governing civil society: The political logic of NGO-State relations under dictatorship," Voluntas, vol. 21, pp. 220-239, 2010.

[22] K. W. Foster, "Associations in the embrace of an authoritarian state: State domination of society?" Studies in Comparative International Development, vol. 35, pp. 84-109, 2001.

[23] M. J. Esman and N. Uphoff, Local organizations: Intermediaries in Rural Development, NY: Cornell University Press, 1984, pp. 121-145.

[24] Z. Deng and Y. Jing, "Building a Chinese civil society," Chinese Social Science Quarterly, vol.1, pp.1-22, 1992.

[25] R. S. Schiller and M. A. Bar, "Revisiting collaborations between nonprofits and businesses: An NPO-centric view and typology," Nonprofit and Voluntary Sector Quarterly, vol. 42, pp. 942-962, 2013.

[26] W. Poortinga and N. F. Pidgeon, "Exploring the dimensionality of trust in risk regulation," Risk Analysis, vol. 23, pp. 961-972, 2003.

[27] M. Siegrist, G. Cvetkovich, and C. Roth, "Salient value similarity, social trust, and risk/benefit perception," Risk Analysis, vol. 20, pp. 353-362, 2000.

[28] G. T. Cvetkovich and P. L. Winter, "Trust and social representations of the management of threatened and endangered species," Environment and Behaviour, vol. 35, pp. 286-307, 2003.

[29] J. Walls, N. Pidgeon, A. Weyman, and T. H. Jones, "Critical trust: Understanding lay perceptions of health and safety risk regulation," Health, Risk, and Society, vol.6, pp. 133-150, 2004.

[30] T. C. Earle and G. T. Cvetkovich, Social Trust: towards a Cosmopolitan Society, London: Praeger, 1995, pp.67-90.

[31] W. L. Knutsen, "Value as a self-sustaining mechanism: Why some nonprofit organizations are different from and similar to private and public organizations," Nonprofit and Voluntary Sector Quarterly, vol. 42, pp. 985-1005, 2013.

[32] K. K. Chen, H. Lune, and E. L. Queen, "How values shape and are shaped by nonprofit and voluntary organizations: The current state of the field," Nonprofit and Voluntary Sector Quarterly, vol. 42, pp. 856-885, 2013.

[33] K. Gaskin, "Blurred vision: Public trust in charities," International Journal of Nonprofit and Voluntary Sector Marketing, Vol. 4, pp. 163-178, 1999.

[34] P. Alcock, "Partnership and mainstreaming: voluntary action under new labour," Third Sector Research Centre, Report number: 32, 2010.

[35] State Council. (October, 2013). Guanyu Zhengfu Goumai Shehui Gongzuo Fuwu De Zhidao Yijian [The guidance of government purchase of social services]. [Online] Available: http://www.mof.gov.cn/zhengwuxinxi/zhengcefabu/201211/t2012112 8_704979.htm

[36] A. Sargeant and S. Lee, "Donor trust and relationship commitment in the U.K. charity sector: The impact on behaviour," Nonprofit and Voluntary Sector Quarterly, vol. 33, pp. 185-202, 2004.

[37] A. Sargeant and S. Lee, "Trust and relationship commitment in the United Kingdom voluntary Sector: Determinants of donor behaviour,' Psychology and Marketing, vol. 21, pp. 613-635, 2004.

[38] N. Bendapudi, S. N. Singh, and V. Bendapudi, "Enhancing helping behaviour: An integrative framework for promotion planning?" Journal of Marketing, vol. 60, pp. 33-49, 1996.

[39] D. Wang, Development of Philanthropy in China: 2001-2011, Beijing: Beijing Normal University Press, 2011.

[40] Y. Ding. (October, 2011). China Public Donation Decreased Sharply in June After Guo Meimei Incident. [Online] Available: http://hausercenter.org/chinanpo/2011/10/china-public-donation-decre ased-sharply-in-june-after-guo-meimei-incident/ See also in Beijing Times, http://politics.people.com.cn/GB/1027/15650482.html

[41] Y. Yang, "Evaluation of public trust in charities of China," M. S. thesis, Beijing Normal University, Beijing, China, 2012. 


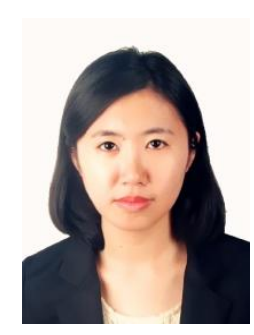

Yongjiao Yang was born in Chongqing, China, 1987. She is a current PhD student in social policy at the University of Hull, UK. Her principal areas of research are public trust in voluntary organizations and comparative study of philanthropy in Eastern and Western countries. She gets full scholarship for $\mathrm{PhD}$ study.

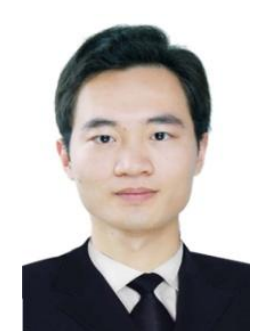

Xiongxiong Zhang was born in Sichuan, China, 1987. He is a second year $\mathrm{PhD}$ candidate in politics and international relations at Durham University, UK. He has completed an LLM in International Law at the University of Glasgow, and then did an MA in politics and international relations at Durham University. His current research interests include the problem of trust in domestic and International politics, the role of international institutions, the security and regional integration in East Asia and U.S.-China relations, especially the strategic distrust in this bilateral relationship.

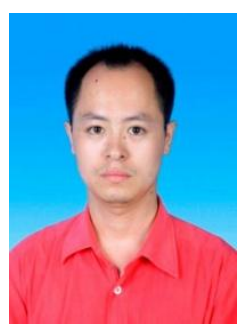

Denglong Tang was born in Tianjing, China, 1979 He got a PhD degree in Beijing Normal University, 2011. He is a current lecture in School of Humanities and Social sciences, University of Science Technology Beijing. He gives lectures on public administration, Chinese government and politics, and management. His research interests include non-profit organizations and public administration.

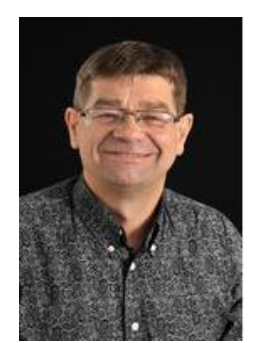

Mick Wilkinson is the director of the Centre for Research on Social Justice in a Globalising World at the University of Hull. He is also a permanent research associate in the Contemporary Slavery Research Centre at the Wilberforce Institute, Hull. His research interests include social justice, slavery in the $21 \mathrm{st}$ century; inequalities and social divisions; poverty and social exclusion; power, resistance and rebellion; migration; refugees and asylum. 